\title{
Production of Platelet-derived Growth Factorlike Protein by Rat Mesangial Cells in Culture
}

\author{
H. E. Abboud, * E. Poptic, ${ }^{\ddagger}$ and P. DiCorleto ${ }^{\ddagger}$ \\ * Department of Medicine, Veterans Administration Medical Center, Case Western Reserve University, and ${ }^{\ddagger}$ Atherosclerosis Section, \\ Division of Cardiovascular Research, The Cleveland Clinic Foundation, Cleveland, Ohio 44106
}

\begin{abstract}
Rat mesangial cells (MC) release a factor that competes in a dose-dependent manner with ${ }^{125}$ I-labeled platelet-derived growth factor (PDGF) for binding to human foreskin fibroblasts (HFF). The competitor activity in mesangial cell conditioned medium (MCCM) is reversible, trypsin sensitive, and inhibited by anti-PDGF IgG. MCCM also expresses potent mitogenic activity to HFF. Anti-PDGF IgG, in concentrations that completely abolished the mitogenic activity of pure PDGF and the competitor activity of MCCM, only partially (33-41\%) inhibits this mitogenic activity. The PDGF receptor competing activity as well as the total mitogenic activity, coelutes with labeled pure PDGF on Sephacryl S-200 gel chromatography. Cation exchange chromatography of concentrated MCCM yields a major mitogen peak with little competitor activity and a smaller mitogenic peak with comparable competitor activity, suggestive of the presence of other mitogens in MCCM besides the PDGF-like protein.

PDGF is a potent mitogen and may play a role at inflammatory sites. The production of PDGF-like protein by MC may provide insights for understanding the pathogenesis of glomerular diseases.
\end{abstract}

\section{Introduction}

Glomeruli, the filtering units of the kidney, are composed of several cell types including epithelial, mesangial and endothelial cells $(1,2)$. Recent studies suggest that glomerular cells are intimately involved in regulating glomerular hemodynamics and actively participate in modulating responses to pathologic stimuli (1-9). The availability of techniques to isolate and culture homogenous preparations of glomerular cells have advanced our knowledge of the functions and properties of intrinsic glomerular cells $(1,2)$. Particular attention has focused on glomerular mesangial cells (MC). ${ }^{1} \mathrm{MC}$ are specialized perivascular cells with diverse characteristics. In addition to their ability to synthesize glomerular basement membrane and me-

\section{Address reprint requests to Dr. Abboud, VA Medical Center, $10701 \mathrm{E}$. Boulevard, Cleveland, OH 44106. \\ Received for publication 3 October 1985 and in revised form 20 February 1987}

1. Abbreviations used in this paper: DVF 12 medium, Dulbecco-Vogt modified Eagle's:Ham 12 medium; HFF, human foreskin fibroblasts; IL-1, interleukin 1; MC, mesangial cells; MCCM, mesangial cell conditioned medium; PAGE, polyacrylamide gel electrophoresis; PDGF, platelet-derived growth factor; PDS, plasma-derived serum.

J. Clin. Invest.

(C) The American Society for Clinical Investigation, Inc.

0021-9738/87/09/0675/09 \$2.00

Volume 80, September 1987, 675-683 sangial matrix components such as collagen and fibronectin, they possess receptors for a number of hormones and inflammatory mediators that may regulate their function in physiologic or pathologic states (4-7). MC exhibit smooth musclelike properties and contract in response to vasoactive hormones (4-7), synthesize potent inflammatory mediators such as oxygen-derived radicals (8), cyclooxygenase and lipooxygenase products $(5,8)$, and release a neutral proteinase capable of digesting glomerular basement membrane (9). Of particular interest are the recent observations that rat glomerular MC produce erythropoietin (10) as well as a mitogen that closely resembles macrophage interleukin 1 (IL-1) (11). While exploring the mitogenic activity of rat mesangial cell conditioned medium (MCCM) on several target cells, we discovered that these cells release a protein indistinguishable immunologically and physiochemically from platelet-derived growth factor (PDGF). PDGF, a heat stable polypeptide, is the major mitogen in serum for a variety of cells of mesenchymal origin (12-16). It is stored in the alpha-granules of platelets and is released into the serum during blood clotting. While platelets are the primary source of this growth factor activity in the serum, several studies have shown that nonplatelet cells are capable of producing and releasing a PDGF-like protein. PDGF or a closely related molecule is synthesized and released by transformed or malignant cells in culture (17-20). The demonstration that PDGF has extensive sequences homology with the putative transforming protein of simian sarcoma virus (15), suggest that PDGF may be involved in the abnormal growth of malignant cells. Recent studies show that PDGF-like protein may also be secreted by nontransformed proliferative cells $(21-25)$. DiCorleto et al. have recently reported that cultured endothelial cells from several species produce several mitogens, one of which is biochemically and immunologically related to PDGF $(21,25)$. This report describes the production by rat cultured MC of a growth factor molecule that shares physiochemical and immunologic characteristics with PDGF. The potential implication of this finding is also discussed.

\section{Methods}

Materials. Human PDGF purified to homogeneity, partially purified human PDGF, and monospecific goat anti-human PDGF IgG were tested for purity and specificity and kindly provided by Dr. Russell Ross, University of Washington, Seattle, WA. PDGF preparations were purified from outdated human platelets through multiple column chromatography steps as previously described (26). Pure PDGF was radioiodinated by the iodine monochloride method $(27,28)$ to a specific activity of $\sim 40,000 \mathrm{cpm} / \mathrm{ng}$. The purity of the PDGF preparation was analyzed by SDS polyacrylamide gel electrophoresis (PAGE) on a $15 \%$ gel followed by autoradiography. The purity of the PDGF preparations used exceeds $90 \%$. Labeled PDGF preparations are routinely tested for mitogenic as well as binding activities (26-28). Antibody to purified human PDGF was prepared in a goat, and purified by 
$\mathrm{Na}_{2} \mathrm{SO}_{4}$ precipitation and chromatography on DEAE-Sephacel. Control IgG from a nonimmunized goat was prepared in the same manner. The anti-PDGF antibody has been shown to specifically block the binding and mitogenic activity of purified human PDGF but not the mitogenic effect of other growth factors such as fibroblast growth factor and epidermal growth factors to target cells (19). The following reagents were obtained from Sigma Chemical Co., St. Louis, MO: Hepes (n-4-(2-hydroxyethyl)-1-piperazine- $N^{\prime}-2$ ethanesulphonic acid) and insulin. Bovine serum albumin for the binding assays was from Armour Pharmaceutical Co. (Kankakee, IL). [Methyl- $\left.{ }^{3} \mathrm{H}\right]$ Thymidine (6.7 $\mathrm{Ci} / \mathrm{mmol}$ ) was purchased from New England Nuclear (Boston, MA). Reagents for angiotensin converting enzyme were purchased as a kit from Boehringer Mannheim Biochemicals (Indianapolis, IN).

Animals. Male Sprague-Dawley rats (Charles River Breeding Laboratories, Wilmington, MA) weighing $125-200 \mathrm{~g}$ were used routinely to provide the MC cultures. In some experiments, as specified, MC were obtained from $2 \mathrm{wk}$ and 3 mo old Sprague-Dawley rats. These rats were bred in our own facility.

\section{Cell cultures}

MC Cultures. MC were obtained from cultures of isolated rat glomeruli as previously described with minor modifications $(2,6)$. Rats were anesthetized with ether and kidneys were excised under sterile conditions. Glomerular isolation was carried out at $0-4^{\circ} \mathrm{C}$, in a laminar flow hood. Renal cortices from three to five rats were pooled, minced with a razor blade, and pressed through a stainless steel sieve, $212 \mathrm{mM}$ pore size. Material that passed through the sieve was suspended in Dulbecco's phosphate-buffered saline (PBS, Gibco Laboratories, Grand Island, NY) contaning $100 \mathrm{U} / \mathrm{ml}$ penicillin, $100 \mu \mathrm{g} / \mathrm{ml}$ streptomycin and $0.25 \mu \mathrm{g} / \mathrm{ml}$ fungizone (Gibco Laboratories). This suspension was subsequently passed through successive Nitex nylon sieves of 250-, $211-, 150-$, and $50-\mu \mathrm{m}$ pore size (Tetko Inc., Rolling Meadows, IL). Glomeruli from the regular size and adult rats were collected from the top of the 50- $\mu \mathrm{m}$ sieve, resuspended, and washed twice with PBS containing the antibiotics. Harvested glomeruli (5-10\% contaminated with tubular fragments) were resuspended in culture medium RPMI 1640 (MA Bioproducts, Walkerville, MD) buffered with $15 \mathrm{mM}$ Hepes at a $\mathrm{pH}$ of 7.4 , supplemented with $17 \%$ decomplemented fetal calf serum (FCS), $0.66 \mathrm{U} / \mathrm{ml}$ insulin, and antibiotics (Gibco Laboratories). Suspended glomeruli were plated onto tissue culture flasks or tissue culture dishes and incubated at $37^{\circ} \mathrm{C}$ in an atmosphere of $95 \%$ air and $5 \%$ carbon dioxide. Cultures were refed with culture medium 3-4 d after plating and medium change was subsequently performed every 48 or $72 \mathrm{~h}$. Under these conditions only glomeruli attach and primary glomerular eipthelial cell outgrowth persists for 5-9 d after plating. After this time period, epithelial cells start to senesce and detach while MC appear and spread from the glomerular cores. These primary cultures of MC were allowed to grow for 3-4 wk, at which time period the cultured cells are confluent MC. Primary confluent MC were washed and removed with $0.025 \%$ trypsin- $0.5 \mathrm{mM}$ EDTA in calcium and magnesium-free PBS. Cells were then suspended in culture medium and plated onto culture dishes or flasks (Costar, Cambridge, MA) as specified. For the glomerular preparation from the young rats, the glomerular suspension was passed through 150-, 105-, and 75- $\mu \mathrm{m}$ sieves, allowed to settle by gravity, and supernatant suctioned slowly by a Pasteur pipette and discarded. This process was repeated two to three times. The $60 \%$ pure glomerular suspension was plated as for the other glomerular preparations. Tubular fragments under these culture conditions never attach and are removed after the first medium change. Unless specified otherwise, experiments were performed on primary or first two passage MC cultures. The identity of the MC were established by several criteria. Morphologic evaluation of the cell cultures was performed as previously described (6). On phase-contrast microscopy, the cells appear as a homogenous population of large, stellate or fusiform cells with prominent intracellular fibrillar structures parallel to the plasma membrane. On electron microscopy, the cells display numerous bundles of microfilaments, elongated nuclei, and dense patches. These morphologic features are similar to those of MC in situ
$(1,2)$. None of the cultures contained cells with epithelial or endothelial features as determined by either phase contrast or electron microscopy. Morphologic features, phase contrast, and electron microscopy, were maintained through 13 serial passages thus far tested. Moreover, the cells were sensitive to mitomycin C, a MC toxin, but not aminonucleoside of puromycin, known to be an epithelial cell toxin $(1,6)$. Fibroblast contamination was excluded by the ability of MC to grow in medium in which $\mathrm{L}$-valine was substituted by $\mathrm{D}$-valine $(1,6)$, a condition in which fibroblasts do not survive. Immunoperoxidase studies on MC, performed on primary and first passage MC, showed positive staining for fibronectin, utilizing rabbit antihuman antiserum (Dako Corp., Santa Barbara, CA). Staining for fibronectin was seen both in the cells and extracellular matrix in agreement with findings by other investigators in MC cultures $(9,11)$ as well as in situ studies (29). Endothelial cell contamination was excluded by the absence of staining for Factor VIII antigen by immunoperoxidase technique utilizing rabbit antihuman antiserum (Dako Corp.) that stained endothelial cells of rat renal cortical blood vessels and human umbilical vein endothelial cells. Moreover rat MC were tested for the presence of the endothelial cell marker, angiotensin converting enzyme (ACE) utilizing a highly sensitive spectrophotometric assay (30). Confluent cultures of primary and first passage rat MC were tested for ACE activity by determining the amount of glycyl-glycine liberated upon incubation of samples with hippuryl-glycyl-glycine. Confluent cultures of human umbilical vein and bovine aortic $\mathrm{EC}$ were used as positive controls. Rat MC did not express any amount of enzyme activity over a wide range of enzyme protein tested. In contrast, intact isolated rat glomeruli and both umbilical vein and bovine aortic EC expressed high and linear enzyme activity within the same protein range of the tested MC preparations.

\section{Other cell cultures}

Human foreskin fibroblasts (HFF) were prepared from tissue provided by the Perinatal Clinical Research Center, Cleveland Metropolitan General Hospital (23). Cultures of bovine aortic EC, and human umbilical vein EC were isolated and maintained as described previously $(21,23,25)$. The medium used for HFF, bovine and human umbilical vein EC was a 1:1 mixture of Dulbecco-Vogt modified Eagle medium with high glucose and Ham F12 (DV12 medium; Gibco Laboratories) supplemented with sodium bicarbonate $(0.23 \%)$, penicillin $(200$ $\mathrm{U} / \mathrm{ml})$, streptomycin $(200 \mu \mathrm{g} / \mathrm{ml})$, nonessential amino acids $(0.2 \mathrm{mM})$, sodium pyruvate $(2 \mathrm{mM})$ and L-glutamine $(4 \mathrm{mM})$. Unless indicated otherwise, these cultures were maintained in medium containing 5\% serum (Hy-Clone, Logan UT).

Preparation of plasma-derived serum. Cell-free plasma-derived serum (PDS) was prepared from citrated whole blood of human volunteers as previously described $(23,30)$. Briefly, blood was collected in prechilled syringes containing sodium citrate, transferred to cold plastic centrifuge tubes and centrifuged to remove all blood cell elements at $30,000 \mathrm{~g}$ for $20 \mathrm{~min}$. Plasma was recalcified by the addition of $\mathrm{CaCl}_{2}$ to a final concentration of $20 \mathrm{mM}$ and allowed to clot for $2 \mathrm{~h}$ at $37^{\circ} \mathrm{C}$. Clotted material was removed by centrifugation at $400 \mathrm{~g}$ for $30 \mathrm{~min}$ at $4^{\circ} \mathrm{C}$. Plasma-derived serum was filter sterilized and stored at $-70^{\circ} \mathrm{C}$.

Preparation of cell free conditioned media. MC were grown to confluence in $22 \mathrm{~mm}$ or $35 \mathrm{~mm}$ multiwell dishes (Costar) in 1 or $2 \mathrm{ml}$, respectively, of MC culture medium (RPMI + FCS). This medium was aspirated and cells washed three times with serum free RPMI containing the antibiotics and buffered with Hepes to $\mathrm{pH} 7.4$ and incubated in the same medium for $24 \mathrm{~h}$. This first medium collection was discarded to exclude any contamination with serum. Subsequent collections were made from cells reincubated with serum free RPMI for $\mathbf{4 8}$ or $\mathbf{7 2}$ h. Medium from wells is collected into conical centrifuge tubes, and centrifuged to remove cell debris at $5,000 \mathrm{rpm}$ for $5 \mathrm{~min}$, in a Sorvall centrifuge. The supernatant was stored at $0-4^{\circ} \mathrm{C}$ until assayed.

Radioreceptor assay for PDGF-like protein. The concentration of PDGF-like protein in MCCM was measured by a radioreceptor assay as previously described $(21,27,28)$. This assay measures the competitive activity of the test sample with ${ }^{125}$ I-PDGF for binding to PDGF 
receptors on HFF. Unlike standard simultaneous competition assays the protocol of this assay involves preincubating the target cells with PDGF standard or test sample, aspirating the medium and adding binding medium containing ${ }^{125}$ I-PDGF. The assay therefore depends on the ability of the bound receptor during the preincubation with purified PDGF or test substance to remain blocked during subsequent incubation with ${ }^{125}$ I-PDGF (28). This sequential incubation protocol excludes detection of spurious amounts of PDGF secondary to binding of the label to binding components in the test sample, and for reasons discussed (19) helps increase the sensitivity of the assay. Subconfluent HFF were plated at a density of $1.5 \times 10^{4}$ cells $/ \mathrm{cm}^{2}$ in 24 well plates in $1 \mathrm{ml}$ medium containing $1 \%$ PDS. Cells were used 4-10 d after plating. Plates were placed on crushed ice and washed with $0.5 \mathrm{ml}$ of ice-cold binding medium. This medium is Dulbecco-Vogt medium without bicarbonate containing $25 \mathrm{mM}$ Hepes buffer $\mathrm{pH} 7.2$ and $2 \mathrm{mg} / \mathrm{ml}$ BSA. Binding medium alone or binding medium containing varying aliquots of MCCM or standard concentrations of pure PDGF was then added to the cells. In the experiments where the effects of anti-PDGF antibody was tested, MCCM or pure PDGF samples were preincubated in the presence or absence of antibody or identical amonts of control IgG in sterile siliconized microcentrifuge tubes for 1 -h at $22^{\circ} \mathrm{C}$ with rotary shaking every $10 \mathrm{~min}$. The concentration of the anti-PDGF IgG was adjusted such that the amount of the antibody relative to the amount of PDGF in all the samples remains constant. Aliquots from each preincubation condition were then transferred to the cells (HFF). Cells were then incubated for $2 \mathrm{~h}$ at $4^{\circ} \mathrm{C}$ with gentle shaking on an oscillating table. Medium was aspirated and cells washed three times with binding medium. $0.5 \mathrm{ml}$ of binding medium containing $0.2 \mathrm{ng}$ ${ }^{125}$ I-PDGF was then added to each well and incubation continued for an additional $2 \mathrm{~h}$ at $4^{\circ} \mathrm{C}$. At the end of this incubation, medium was aspirated and cells washed three times with $1 \mathrm{ml}$ ice-cold PBS containing $B S A$ at $1 \mathrm{mg} / \mathrm{ml}$ and $1 \mathrm{mM} \mathrm{Ca}^{2+}$. Bound radioactivity was determined by solubilizing the cells with $1 \%$ Triton $X-100$ containing BSA 1 $\mathrm{mg} / \mathrm{ml}$. PDGF-like protein was quantitated from standard curves obtained from wells containing $0.05,0.1$, and $0.2 \mathrm{ng}$ unlabeled pure PDGF. Nonspecific binding was determined as the amount of ${ }^{125} \mathrm{I}$ PDGF bound in the presence of 100 -fold excess of partially purified PDGF and averaged 5\%. Data were expressed as nanograms PDGF equivalent $/ 10^{5}$ cells. In some experiments, PDGF-like protein was also expressed as units of competitor activity, where one unit is equivalent to $1 \%$ inhibition of ${ }^{125} \mathrm{I}$ binding. Competitor activity of all samples and standards were determined in duplicate or triplicate wells. In one experiment, and to exclude a damaging effect of MCCM on the PDGF receptor, we also tested the effect of acetic acid wash on the competitor activity of MCCM for the subsequent binding of ${ }^{125}$ I-PDGF $(31,32)$. Duplicate dishes of HFF were incubated at $4^{\circ} \mathrm{C}$ for $2 \mathrm{~h}$ with MCCM, crude PDGF, or binding medium as described earlier for the radioreceptor assay. One group of dishes representing each incubation condition was subsequently washed with binding medium while the other group was washed with binding medium followed by a 3-min incubation at $4^{\circ} \mathrm{C}$ with $0.2 \mathrm{M}$ acetic acid in $150 \mathrm{mM} \mathrm{NaCl}$ with $1 \mathrm{mg} / \mathrm{ml} \mathrm{BSA}$, pH 3.12. All dishes were subsequently washed twice with binding medium and ${ }^{125}$ I-PDGF binding determined as described earlier.

Mitogenic activity of PDGF-like protein. The growth-promoting activity of MCCM was determined by measuring the incorporation of $\left[{ }^{3} \mathrm{H}\right]$ thymidine by serum-free cultures of $\operatorname{HFF}(21,23,31)$. HFF grown in medium containing $5 \%$ bovine serum were plated in 24 well dishes at a density of $3 \times 10^{4}$ cells $/ \mathrm{cm}^{2}$ in $1 \%$ PDS. Cells were used after $5 \mathrm{~d}$ when they were quiescent and nondividing. Triplicate aliquots of MCCM or pure PDGF were preincubated in the absence or presence of goat antihuman PDGF IgG in sterile siliconized microcentrifuge tubes for $1 \mathrm{~h}$ at $22^{\circ} \mathrm{C}$ with rotary shaking every $10 \mathrm{~min}$. The concentration of the anti-PDGF IgG was adjusted such that the ratio of the amount of antibody relative to PDGF in all the samples remains constant and identical to that in the radioreceptor assay. Control incubations consisted of aliquots of pure PDGF incubated with control IgG and MCCM also incubated with IgG. The mitogenic activity of the preincubated samples was determined as follows: Sample content from each tube was divided into two aliquots and added to each well of HFF cultures in the 24 well plates in 1\% PDS in DVF 12 medium supplemented with sodium bicarbonate, sodium pyruvate, L-glutamine, penicillin, streptomycin and nonessential amino acids. Cultures were then incubated for $18 \mathrm{~h}$ at $37^{\circ} \mathrm{C}$. Incubation medium was then aspirated and replaced with fresh DVF12 medium containing $\left[{ }^{3} \mathrm{H}\right]$ thymidine $(0.5 \mu \mathrm{Ci} / \mathrm{ml})$ in a total volume of $0.5 \mathrm{ml}$ and cells reincubated for 4 $h$ at $37^{\circ} \mathrm{C}$. The assay was terminated by aspiration of the medium and washing the cells twice with 5\% TCA. Cells from individual wells were harvested by the addition of $0.7 \mathrm{ml}$ of $0.25 \mathrm{NaOH}$ and the radioactivity in $0.5-\mathrm{ml}$ aliquots was determined by liquid scintillation counting.

To determine the ratio of mitogenic to competitor activity present in MCCM, pooled MCCM was concentrated 20-fold by ultrafiltration (Amicon Corp., Danvers, MA; YM-10 membrane) and centrifuged. Mitogenic and competitive activities were assayed as described earlier on serial dilutions of the concentrate of MCCM in the presence of standard concentrations of PDGF in both assays.

Biochemical characterization of competitor activity in MCCM: Effect of trypsin. Serum free MCCM was collected as described earlier, concentrated 36 fold by ultrafiltration (YM-10 membrane) and centrifuged. A 1-ml aliquot of this concentrate was incubated with $300 \mu \mathrm{g}$ of trypsin at $37^{\circ} \mathrm{C}$ for $1 \mathrm{~h}$. Soybean trypsin inhibitor $(660 \mu \mathrm{g})$ was then added to neutralize trypsin. The same concentration of soybean trypsin inhibitor was added to another $1.0-\mathrm{ml}$ aliquot as control. Aliquots were stored at $4^{\circ} \mathrm{C}$, till assayed. PDGF-like competitive activity was assayed on serial dilutions of both aliquots.

\section{Gel chromatography}

Collected serum free MCCM was concentrated 20-fold and dialyzed against $50 \mathrm{mM}$ ammonium acetate $\mathrm{pH} 7.5 .1 .5 \mathrm{ml}$ of this concentrate was applied to a column of Sephacryl S-200 (Pharmacia Fine Chemicals, Piscataway, NJ) equilibrated in $1.0 \mathrm{M}$ acetic acid adjusted to $\mathrm{pH}$ 3.0 with concentrated $\mathrm{NH}_{4} \mathrm{OH}$. Collected fractions were lyophilized, reconstituted in $5 \mathrm{mM}$ acetic acid and monitored for mitogenic and competitor activity as described earlier. An aliquot of ${ }^{125}$ I-labeled pure PDGF was added to the MCCM before elution and fractions were tested for radioactivity in a gamma counter.

\section{Ion exchange chromatography}

MCCM was concentrated as described earlier, and the concentrated solution dialyzed exhaustively against $1 \mathrm{mM} \mathrm{NH}_{4} \mathrm{HCO}_{3}, \mathrm{pH} 8.0$ and adjusted to $0.1 \mathrm{M} \mathrm{NH}_{4} \mathrm{HCO}_{3}$ by the addition of $\mathrm{NH}_{4} \mathrm{HCO}_{3}$. This solution was applied to a $1.5 \times 28 \mathrm{~cm}$ column of CM Sephadex G-50 equilibrated at room temperature with $0.1 \mathrm{M} \mathrm{NH}_{4} \mathrm{HCO}_{3}, \mathrm{pH}$ 8.0. After washing, a linear gradient of $\mathrm{NH}_{4} \mathrm{HCO}_{3}$ from 0.1 to $1.0 \mathrm{M}$ was started. Fractions were lyophilized and resuspended in $5 \mathrm{mM}$ acetic acid containing $2 \mathrm{mg} / \mathrm{ml} \mathrm{BSA}$ and were assayed for PDGF competitor and total mitogen activity.

\section{Results}

In preliminary experiments, and using the radioreceptor assay, we found that preincubation of increasing concentrations of MCCM with HFF inhibit the subsequent binding of ${ }^{125} \mathrm{I}$ PDGF to the cells in a dose-dependent manner. In contrast to the effect of MCCM, control (nonconditioned serum-free RPMI), at various concentrations, had no effect on ${ }^{125}$ I-PDGF binding to the same fibroblast cultures.

Table I shows the concentration of PDGF-like protein released into conditioned medium of confluent primary and first passage MC from four separate MC cell cultures. Since the molecule released by rat mesangial cells may not be identical to human PDGF, the concentration of this molecule was expressed as "ng PDGF equivalent" rather than PDGF. When expressed per cell number, the competitor activity released by MC does not decline with cell passage. We observed that MC 
Table I. Production of PDGF-like Protein by Rat Mesangial Cells in Culture

\begin{tabular}{ll}
\hline & PDGF \\
\hline & $n g$ eq/72 h/10 cells \\
Culture 1 & \\
Primary (days 0-3) & $3.25 \pm 0.1$ \\
Primary (days 3-6) & $3.35 \pm 0.1$ \\
Passage I (days 0-3) & $3.60 \pm 0.0$ \\
Passage I (days 3-6) & $2.80 \pm 0.0$ \\
Culture 2 & \\
Primary (days 0-3) & $1.59 \pm 0.03$ \\
Primary (days 3-6) & $1.79 \pm 0.01$ \\
Passage I (days 0-3) & $2.06 \pm 0.39$ \\
Passage I (days 3-6) & $2.76 \pm 0.66$ \\
Culture 3 (2 wk old) & \\
Primary (days 0-3) & 2.47 \\
Primary (days 3-6) & 2.92 \\
Culture 4 (3 mo old) & \\
Primary (days 0-3) & 1.11 \\
Primary (days 3-6) & 1.96
\end{tabular}

Primary cultures of confluent MC were obtained from isolated glomeruli plated onto multiwell culture dishes. Cells were passaged using trypsin-EDTA into same size dishes and grown to confluence in RPMI containing FCS. Serum-free conditioned media were collected every $72 \mathrm{~h}$ as described in Methods and PDGF-like protein assayed on aliquots of the conditioned media by radioreceptor assay. Data shown are median \pm range of values on media from at least two culture wells, each assayed in duplicates, except for the experiment on the young and old rats where values are from single collection wells each assayed in duplicate. Cell counts were obtained from the same wells at the end of each collection period or from wells co-cultured and coincubated for conditioned media in an identical manner. Cells were treated with trypsin-EDTA and counted on a hemocytometer.

continue to release this competitor activity up till eight passages thus far tested (unpublished observations). Smooth muscle cells cultured from pup but not adult rats have recently been shown to release a PDGF-like molecule (22). Since MC share several properties with smooth muscle cells, we measured the concentration of PDGF-like activity in conditioned media of MC cultured from 2-wk-old and 3-mo-old adult rats. MC from both groups of rats exhibited similar morphologic characteristics by phase contrast and electron microscopy. Unlike the marked difference in PDGF production between pup and adult smooth muscle cells, there was no major difference in PDGF production by MC from both the young and adult rats. Fig. 1 shows that confluent mesangial cells continue to secrete PDGF-like protein into serum free medium for at least 2 wk. This finding suggests that the presence of the protein molecule in the conditioned medium was due to continuous synthesis and secretion rather than release of a prestored pool.

To determine if the substance(s) released into MCCM act by displacing ${ }^{125} \mathrm{I}-\mathrm{PDGF}$ binding to the PDGF receptor on the HFF rather than by a nonspecific effect, we examined the effect of preincubating pure PDGF standards or increasing concentration of MCCM with anti-PDGF IgG on the subsequent binding of ${ }^{125}$ I-PDGF to HFF. Control aliquots were

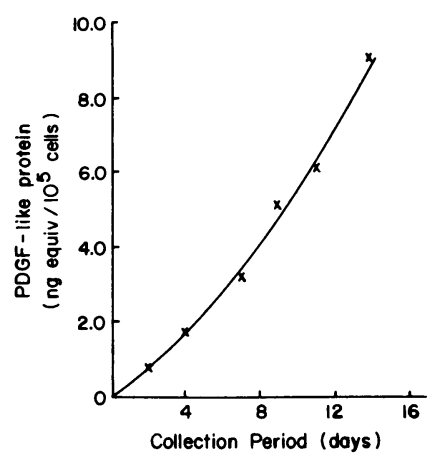

Figure 1. Time course of the production of the PDGF-like protein by rat cultured mesangial cells. Confluent mesangial cells in 35-mm wells were incubated in serum free RPMI. Every 48 or $72 \mathrm{~h}$ this medium was collected and cells counted, and the medium in the remaining wells was replaced with fresh serum-free medium. Aliquots of the collections were assayed for

PDGF-like protein by radioreceptor assay. Values represent the cumulative average of duplicate incubation wells for each time period each assayed in duplicate.

preincubated with an equivalent amount of $\mathrm{IgG}$. As shown in Fig. $2 a$, preincubation with anti-PDGF antibody totally abolishes the competitor activity of the pure PDGF standards confirming the potency of the antibody employed. These same concentrations (relative to PDGF) of anti-PDGF antibody also essentially eliminated the PDGF receptor competing activity in the MCCM Fig. $2 b$. These data show that the PDGFlike substance released into MCCM is recognized by human anti-PDGF. To demonstrate that the inhibitory effect of MCCM on ${ }^{125}$ I-PDGF binding to HFF was not secondary to damage, proteolytic or otherwise, of the PDGF receptor, we determined the effect of acetic acid wash on ${ }^{125}$ I-PDGF to HFF. Acetic acid treatment has previously been shown to be a convenient method to remove cell bound growth factors such as EGF or PDGF (31-33). As expected, preincubation of HFF with crude PDGF or MCCM resulted in a marked decrease in ${ }^{125} \mathrm{I}$-PDGF binding as compared to control cells preincubated with binding medium alone (Fig. 3, closed bars). Acetic acid treatment (hatched bars) fully restored ${ }^{125}$ I-PDGF binding to HFF preincubated with MCCM or crude PDGF. These data support the conclusion that MCCM contains a molecule that interferes with ${ }^{125}$ I-PDGF binding to its receptors on HFF in a reversible manner without damaging the receptor. The small decrease in ${ }^{125} \mathrm{I}-\mathrm{PDGF}$ binding to control HFF following the acid wash is most likely due to minor damage to the receptor.

Since PDGF is a potent mitogen that enhances the proliferation of target cells, e.g., HFF, we next examined the effect of pure PDGF and MCCM on the proliferative response of HFF, measured as $\left[{ }^{3} \mathrm{H}\right]$ thymidine incorporation into DNA. We also determined the effect of anti-PDGF IgG on this proliferative response in the same cell cultures. Pure PDGF markedly enhanced DNA synthesis in quiescent HFF cultures in a dosedependent manner. Average and range of $\left[{ }^{3} \mathrm{H}\right]$ thymidine uptake (counts per minute) increased from $91 \pm 11$ to $393 \pm 2$, $751 \pm 72$, and $1,066 \pm 9.0$ at $0.09,0.18$, and $0.36 \mathrm{ng}$ PDGF, respectively. Preincubation of pure PDGF aliquots with antiPDGF antibody but not with control nonimmune IgG totally abolished the mitogenic effect of PDGF on HFF. Corresponding $\left[{ }^{3} \mathrm{H}\right]$ thymidine counts changed from $91 \pm 11$ to $118 \pm 17$, $133 \pm 12$, and $128 \pm 7.0$ in the presence of anti-PDGF antibody and to $305 \pm 14,485 \pm 24$, and $1,044 \pm 31$, in the presence of control IgG. These data demonstrate the ability of the antibody to recognize the mitogenic moiety of the PDGF protein Fig. 4 a. MCCM also enhanced DNA synthesis by HFF in a concentration-dependent manner. $\left[{ }^{3} \mathrm{H}\right]$ Thymidine uptake in- 

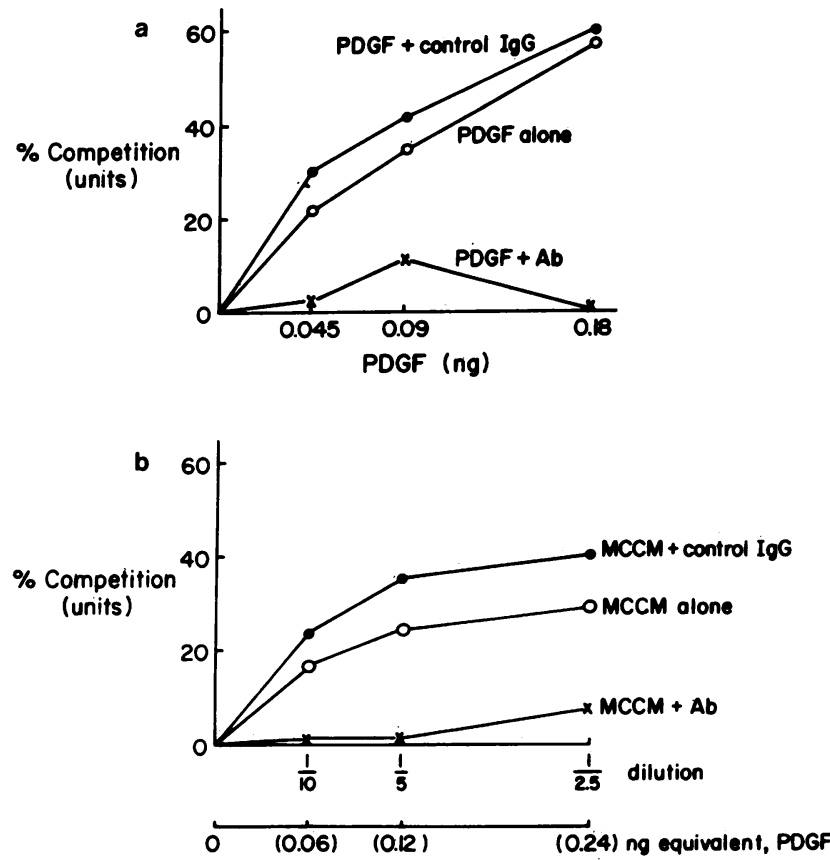

Figure 2. Competitor activity of human PDGF and MCCM for ${ }^{125} \mathrm{I}-$ PDGF binding to HFF: effect of anti-PDGF IgG. Increasing standard concentrations of pure PDGF or serial dilutions of MCCM were preincubated alone or with goat anti-PDGF IgG or control (nonimmune) purified IgG in binding medium as described in Methods. Each preincubation condition was performed at three different concentrations. Aliquots of these mixtures were then transferred to quiescent subconfluent cultures of HFF plated onto 24 well cluster dishes for assay. The following test conditions were assayed for competitor activity in duplicates: (a) standard concentrations of pure PDGF 0.045, 0.09; and $0.18 \mathrm{ng}(0)$, same concentrations of pure PDGF and increasing concentrations of goat anti-PDGF IgG (x), same concentrations of pure PDGF and control IgG in identical amounts to goat anti-PDGF (o). (b) Increasing concentrations of MCCM containing shown amounts of PDGF equivalent (o), same concentrations of MCCM and increasing concentrations of goat antiPDGF IgG ( $x$ ), same concentrations of MCCM and control IgG in identical amounts to goat anti-PDGF IgG (0). Incubation volume for the binding assay was $450 \mu \mathrm{l} /$ well. All wells were adjusted to contain the same amounts of binding medium and vehicle for pure PDGF, goat anti-PDGF IgG and control IgG. Binding assay and competitor activity of each test conditions were determined as described in Methods. $1 \mathrm{U}$ of competitor activity $=1 \%$ inhibition of ${ }^{125}$ I-PDGF binding. MCCM was obtained from a primary culture. Note that anti-PDGF IgG but not control IgG abolished the competitor activity of pure PDGF and competitor activity of MCCM.

creased from $91 \pm 11$ to $421 \pm 3,621 \pm 83$, and $708 \pm 36$. However, the mitogenic activity of MCCM, unlike the competitor activity, was only partially blocked by preincubating the conditioned medium with anti-PDGF antibody. Only $33-41 \%$ of the mitogenic activity of MCCM was blocked with anti-PDGF antibody in concentrations that totally abolished the mitogenic activity of equivalent concentrations of pure PDGF and the competitive activity of MCCM. Preincubation with control nonimmune IgG, on the other hand, had no significant effect on the mitogenic activity of MCCM. Comparable counts in the presence of anti-PDGF IgG were $305 \pm 16,405 \pm 48$, and $495 \pm 24$, and $342 \pm 9,581 \pm 17$, and $629 \pm 47$, in the presence of control IgG Fig. $4 \mathrm{~b}$. These data suggest the presence of multiple mitogens in MCCM, one of which is recognized by the anti-PDGF antibody.

When equal aliquots from the same concentrated sample of MCCM were assayed for competitive and mitogenic activity, the concentration of PDGF-like activity in the mitogenic assay was $26.7 \pm 4.8$ and in the competitor assay $2.20 \pm 0.11 \mathrm{ng}$ PDGF eq/ml (mean \pm SD of triplicate aliquots), a ratio of 12:1. We also studied the effect of the proteolytic enzyme trypsin on the competitor activity of MCCM. Trypsin treatment of three aliquots of concentrated MCCM containing $>0.1 \mathrm{ng}$ PDGF equivalent and providing $>50 \%$ competition resulted in a complete loss of the competitor activity, documenting the peptide nature of the molecule.

Sephacryl S-200 molecular sieving of a concentrate of MCCM under dissociating conditions (1\% acetic acid, $\mathrm{pH} 3.0$ ), revealed a broad peak of PDGF-like protein that contained both the competitor and the mitogenic activity, this peak coeluted with pure ${ }^{125}$ I human PDGF indicating a similar molecular weight (Fig. 5). The appearance of all the mitogenic activity within this broad peak suggest that the molecular weight of the other mitogens falls within the same range, of the PDGFlike protein.

The gel chromatography step does not separate the PDGF from the non-PDGF mitogen. Since PDGF is a highly cationic protein, concentrated MCCM was subjected to cation exchange chromatography and collected fractions were analyzed for competitor and mitogenic activity. Using this ion exchange chromatography, the mitogenic activity eluted into two peaks. The first and least cationic peak contained the bulk of the mitogen activity and measurable PDGF-like competitor activity while the second minor mitogen peak had a comparable amount of mitogenic and competitor activity (Fig. 6). The measurable competitor activity seen in the first mitogen peak is likely due to column overloading. It constitutes only a small fraction of the total mitogen activity present in the first peak hence, the inability of the antibody to have measurable effect on the total mitogen activity present in this peak. The presence of near equal amounts of competitor and mitogen activities in the second peak and the fact that anti-PDGF IgG inhibits $70 \%$ of this mitogen activity $(1.6 \pm 0.1$ with $\mathrm{IgG}$ vs. $0.48 \pm 0.06$ with

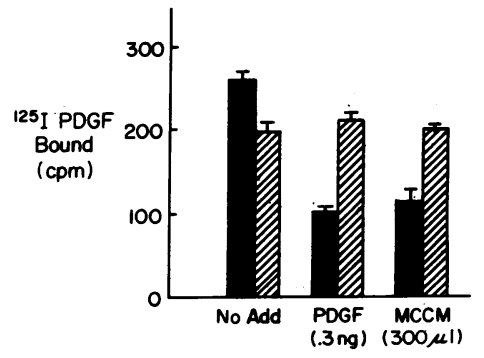

Figure 3. Effect of acetic acid treatment on the competitor activity of MCCM. Duplicate cultures of HFF were preincubated at $4^{\circ} \mathrm{C}$ with rotary shaking for $2 \mathrm{~h}$ with binding medium alone, or binding medium containing either crude PDGF (0.3 ng PDGF equivalent) or an aliquot of MCCM. Cells were then washed with ice cold binding medium and incubated in the same medium ( $($ ) or a solution containing $20 \mathrm{mM}$ acetic acid, $150 \mathrm{mM} \mathrm{NaCl}$ and $1 \mathrm{mg} / \mathrm{ml} \mathrm{BSA}, \mathrm{pH} 3.12$ at $4^{\circ} \mathrm{C}$ for 3 min (⿴). After additional washing with binding medium, cells were incubated with ${ }^{125} \mathrm{I}-\mathrm{PDGF}$ for $2 \mathrm{~h}$ at $4^{\circ} \mathrm{C}$ and bound ${ }^{125} \mathrm{I}$-PDGF was determined as described for the binding assay. Note that following the acid wash, ${ }^{125}$ I-PDGF binding to HFF preincubated with cold PDGF or MCCM is similar to control HFF that were preincubated with binding medium alone (no addition). 

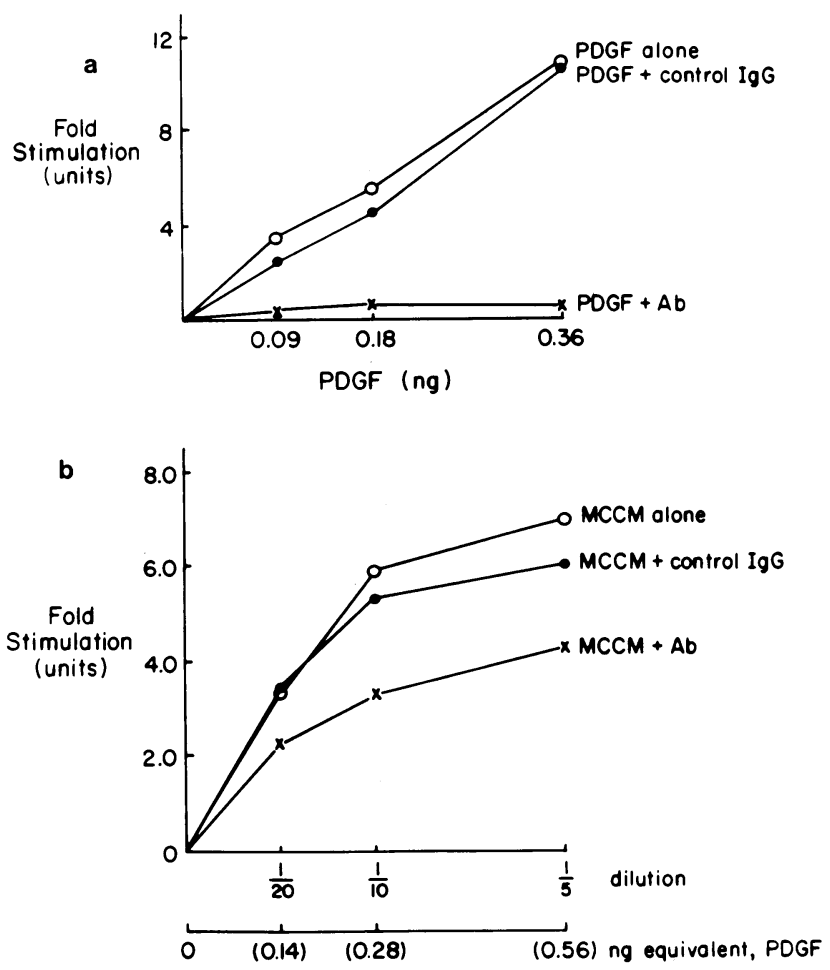

Figure 4. Mitogenic activity of human PDGF and MCCM. Effect of anti-PDGF IgG: Standard concentrations of pure PDGF and MCCM were preincubated with or without anti-PDGF IgG or control IgG. Each preincubation condition was performed at three different concentrations. Mitogenic activity of aliquots from each preincubation condition was determined by $\left[{ }^{3} \mathrm{H}\right]$ thymidine incorporation as described in Methods. HFF $\left(3 \times 10^{4}\right.$ cells/well $)$ were plated onto 24 well Costar dishes in DVF12 medium containing 1\% PDS for $4 \mathrm{~d}$ to insure cell quiescence. The following preincubation conditions were tested for their mitogenic activity: (each condition was tested in duplicate incubation wells): (a) Standard concentrations of pure PDGF $0.09,0.18$ and $0.36 \mathrm{ng}(0)$; same concentrations of pure PDGF and increasing concentrations of goat anti-PDGF $\operatorname{IgG}(\mathrm{x})$; and same concentrations of pure PDGF and control purified IgG in identical amounts to goat anti-PDGF IgG (o). (b) Increasing concentrations of MCCM (o); same concentrations of MCCM and increasing concentrations of goat anti-PDGF IgG (x); same concentrations of MCCM and control IgG in identical amounts to goat anti-PDGF IgG (o); final incubation volume was $1.2 \mathrm{ml}$. Cells were then incubated for 18 $h$ at $37^{\circ} \mathrm{C} .\left[{ }^{3} \mathrm{H}\right] \mathrm{Thymidine}$ incorporation was determined as described in Methods. The data are expressed as ratio of $\left[{ }^{3} \mathrm{H}\right]$ thymidine incorporation by cells in the presence of the addition mixtures to incorporation of $\left[{ }^{3} \mathrm{H}\right]$ thymidine in the control cells (containing medium alone) minus 1 .

anti-PDGF; nanograms PDGF equivalents median and range of duplicate determinations) support the contention that the major portion of this peak represent the PDGF-like protein.

\section{Discussion}

These studies demonstrate that rat smooth muscle-like MC in culture secrete into serum free medium a protein molecule that shares several characteristics with purified human PDGF. We and others $(21,27,31,32)$ have previously shown that purified PDGF demonstrates high affinity binding to specific receptors on target cells such as Swiss 3T3 cells and diploid human fibroblasts and that this binding can be competed for only by purified PDGF but not by any of the other known growth factors such as mouse epidermal growth factor, partially purified fibroblast growth factor, and insulin. Moreover, monospecific goat antihuman PDGF IgG completely abolishes both the competitor and mitogenic activity of pure human PDGF $(25,31,32)$. Several observations support the close similarity of the molecule released by MC to pure PDGF. MCCM inhibits the binding of pure ${ }^{125}$ I-PDGF to its receptors on target cells in a concentration-dependent manner. In addition, antiserum to PDGF in concentrations that abolished the competitor activity of pure PDGF, also abolished the competitor activity present in the MCCM. It has been shown that MC release a neutral proteinase (9). This enzyme is potentially capable of damaging the PDGF receptor thereby decreasing the binding of pure ${ }^{125}$ I-PDGF. Acetic acid treatment of the HFF, however, completely reversed the inhibitory effect of MCCM on ${ }^{125}$ I-PDGF binding excluding a damaging effect of MCCM on the PDGF receptor. These data suggest that MCCM contain a molecule(s) that binds to the PDGF receptor on HFF in a specific manner and that this binding molecule is recognized by the anti-PDGF antibody.

In addition to its competitor activity, MCCM similar to PDGF possesses a potent mitogenic activity to HFF. Experiments utilizing anti-PDGF antibody, show that while this antibody completely abolishes the mitogenic activity of pure PDGF on HFF, it only partially inhibits the mitogenic activity of MCCM. The inability of the antibody to PDGF to remove all the mitogenic activity from MCCM is most likely due to the presence of multiple mitogens in the conditioned medium one of which is similar to PDGF and is recognized by anti-PDGF antibody. It is also possible, that the differential effect of antiPDGF antibody on the mitogenic effect of pure human PDGF and MCCM reflect differences in the antigenic determinants between the human platelet PDGF and the rat mesangial PDGF-like molecule. This possibility is unlikely, however, in view of our finding that the anti-PDGF antibody employed, completely abolished the competitor activity of MCCM. The high ratio of mitogenic to competitive activities present in MCCM also suggests that MC secrete other mitogens besides PDGF. It should be emphasized that while the radioreceptor assay determines molecules that are able to bind to the PDGF receptor, the mitogen assay determines the combined effect of all mitogens present. The production of multiple mitogens by cultured diploid cells is not a unique feature of the MC. PDGF-like molecules account for only a small percentage of the mitogenic activity produced in serum-free medium conditioned by human vascular endothelial cells in culture $(21,25)$.

Physiochemical characterization of the PDGF-like activity of the MCCM also revealed similarities with purified human PDGF. PDGF-like activity in MCCM similar to purified PDGF is sensitive to trypsin confirming the peptide nature of this molecule. Gel filtration chromatography on Sephacryl S-200 provide further evidence of the similarity of this molecule to PDGF. Both the PDGF-like competitor activity and the total mitogenic activity present in MCCM coeluted with pure labeled PDGF, indicating a similar molecular weight. While the gel chromatography step shows that the total mitogen activity elutes under a broad peak and does not separate the PDGF-like from the non-PDGF-like mitogen, the data with the ion exchange chromatography clearly shows the pres- 


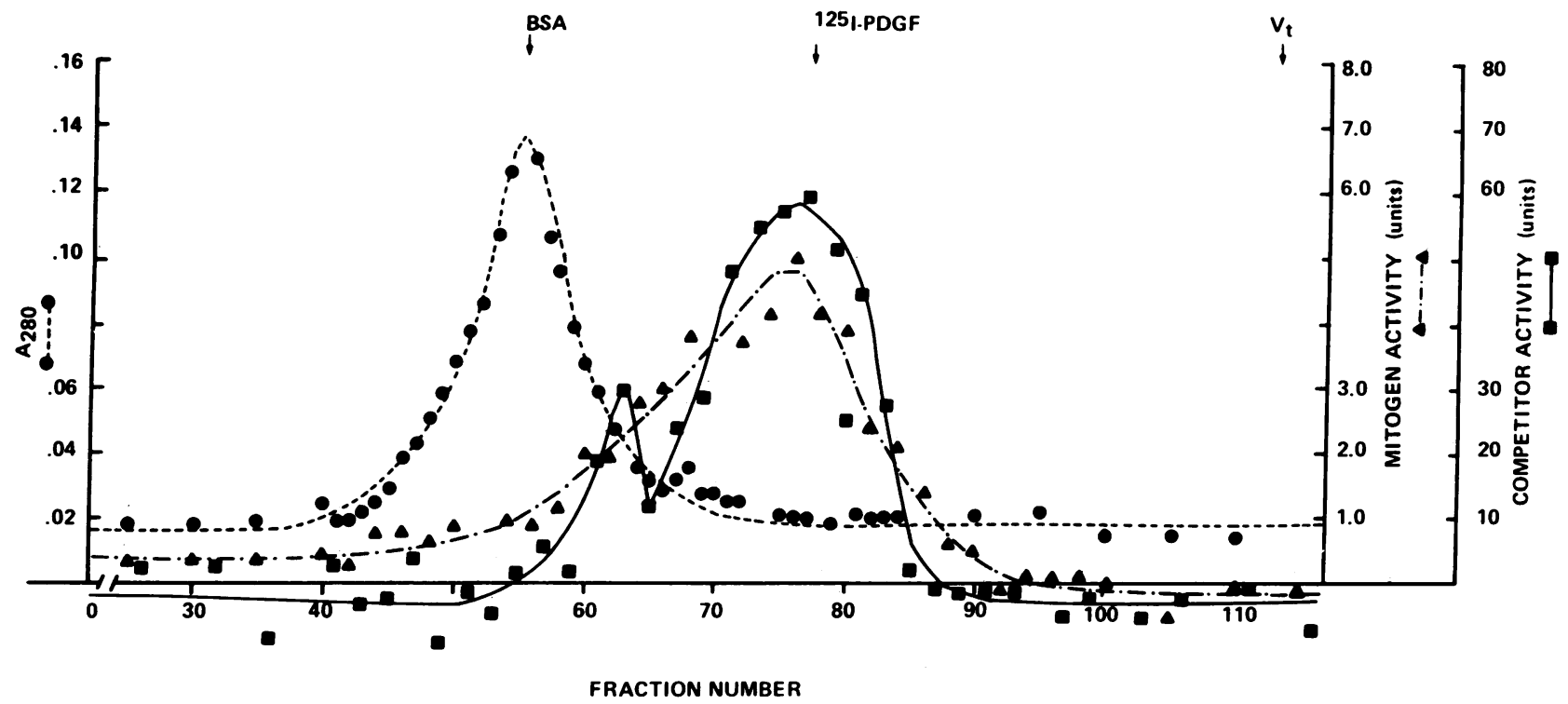

Figure 5. Gel filtration chromatography of mesangial cell conditioned media: A Sephacryl S-200 column $(1.5 \times 47 \mathrm{~cm})$ was equilibrated at room temperature with $1 \mathrm{M}$ acetic acid adjusted to $\mathrm{pH} 3.0$ with concentrated ammonium hydroxide. MCCM was concentrated 20-fold by ultrafiltration through a YM-10 membrane (Amicon). The concentrated solution was dialyzed against $50 \mathrm{mM}$ ammonium acetate (pH 7.5). A $1.5-\mathrm{ml}$ aliquot (3 $\mathrm{mg}$ protein) was adjusted to 1 $\mathrm{M}$ acetic acid, pH. 3.4 using glacial acetic acid. ${ }^{125} \mathrm{I}$-labeled platelet derived growth factor ( $9000 \mathrm{cpm}, 0.5 \mathrm{ng}$ with $1 \mathrm{mg} / \mathrm{ml} \mathrm{BSA})$ was

ence of two mitogenic activities, one of which can be attributed to the PDGF-like protein.

The PDGF concentration in media conditioned by MC range from 1.1 to $3.6 \mathrm{ng}$ PDGF equivalent, and does not appear to decline with cell passage. MC are not the only nontransformed cells capable of producing PDGF-like molecule. Endothelial cell cultures from several species produce a PDGF-like molecule. Seifert et al. (17) recently reported that cultured rat aortic smooth muscle cells from young rats (13-18 days old) but not adult rats also secrete a molecule with binding and mitogenic properties similar to PDGF. Unlike smooth muscle cells, MC cultured from adult and pup rats produce similar amounts of PDGF-like molecule.

The exact biologic role of PDGF-like protein produced by MC remains to be determined. However, our finding and observations by other investigators raise several possibilities. There is increasing evidence that PDGF may play an important role at inflammatory sites (33-39). Recent studies have shown that PDGF is a potent chemoattractant protein for human neutrophils, monocytes (33-35), fibroblasts (36), and smooth muscle cells $(37,38)$. Moreover, PDGF activates neutrophils and monocytes with subsequent release of potent inflammatory mediators such as superoxide anion and lysosmal enzymes $(39,40)$. Both neutrophils and monocytes are prominent components of the glomerular hypercellularity observed in a number of immune inflammatory glomerular diseases observed in experimental animals and man $(41,42)$. In vivo and in vitro studies in animals models of glomerular diseases have established a central role for these inflammatory cells in mediating the changes not only in renal hemodynamics and proteinuria, but also in glomerular cell proliferation (43). Pro- added to the sample as a marker. This solution was then applied to the column at a rate of $2.5 \mathrm{ml} / \mathrm{hr}$, eluted with $1 \mathrm{M}$ acetic acid $(\mathrm{pH}$ 3.0) and collected in $0.75-\mathrm{ml}$ fractions. Elution of ${ }^{125} \mathrm{I}$-labeled PDGF was monitored by gamma scintillation counting. Protein levels were determined by measuring the absorbance at $280 \mathrm{nM}$. All fractions were then lyophilized, resuspended in $5 \mathrm{mM}$ acetic acid with 1 $\mathrm{mg} / \mathrm{ml}$ bovine serum albumin, and assayed for PDGF-like competitor and mitogen activity. $31 \mathrm{U}$ PDGF-like activity $=0.1 \mathrm{ng}$ pure PDGF. $3 \mathrm{U}$ mitogen activity $=0.1 \mathrm{ng}$ pure $\mathrm{PDGF}$.

duction and release of PDGF by MC by attracting and activating inflammatory cells may contribute not only to the glomerular hypercellularity, but also to the resulting alterations in glomerular functional parameters. Of note is that the concentration of the PDGF-like molecule detected in the MCCM is capable of effectively competing with labeled PDGF binding as well as enhancing the proliferation of HFF. Moreover, this concentration falls within the range of PDGF levels required for maximum neutrophil chemotoxis (15). The precise biologic role of the PDGF-like protein secreted by MC, however, awaits further characterization of its molecular and functional similarity to purified PDGF, as well as its availability in situ at target receptors.

It is well known that PDGF is the principle mitogen present in serum for a number of cells of mesenchymal origin including fibroblasts, 3T3 cells, smooth muscle cells and glial cells (12-15). MC also originate from the mesenchyme (45). It was recently reported by Lovett et al. (46) that an IL-1-like activity released into the supernatants of activated macrophages enhance the proliferation of well characterized rat MC only in the presence of serum. No effect on MC proliferation was observed in the presence of platelet poor plasma or serum depleted of PDGF. These authors suggested that PDGF may act as a competence factor that renders $M C$ responsive to the proliferative effect of IL-1-like activity. Such a competence role for PDGF has been proposed for other cultured cells such as 3 T3 cells (13). Striker et al. (47) have also shown that serum containing platelet growth factors enhances the proliferation of well characterized human cultured MC. Moreover, crude platelet lysates have been shown to stimulate rabbit glomerular cells, probably of mesangial origin, to proliferate (48). These 


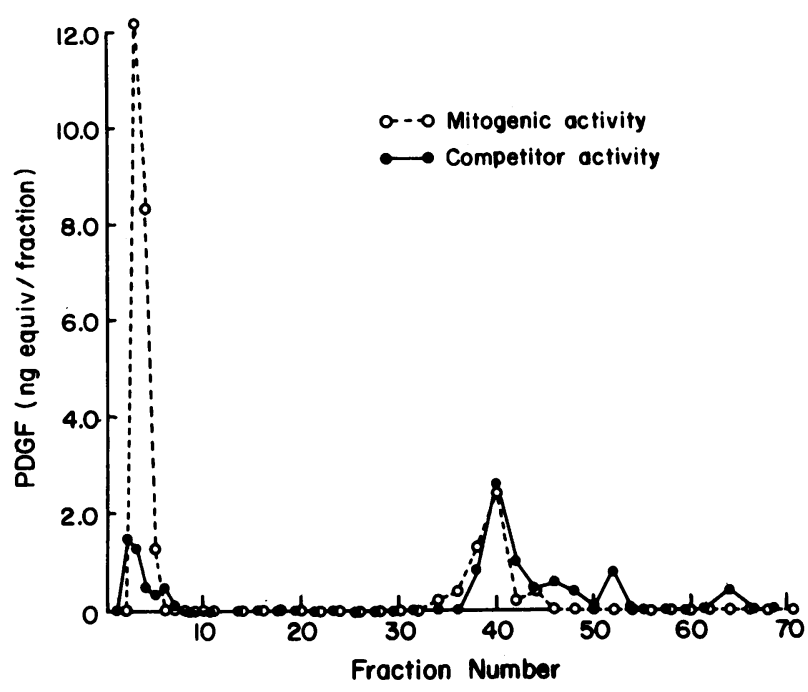

Figure 6. Ion exchange chromatography of rat mesangial conditioned medium. A $1.5 \times 28 \mathrm{~cm}$ column of CM- Sephadex G-50 was equilibrated at room temperature with $0.1 \mathrm{M} \mathrm{NH}_{4} \mathrm{HCO}_{3} \mathrm{pH}$ 8.0. Mesangial cell conditioned medium was concentrated 40 -fold by ultrafiltration through a YM-10 membrane (Amicon). The concentrated solution $(10.45 \mathrm{ml})$ was exhaustively dialyzed against $1 \mathrm{mM} \mathrm{NH}_{4} \mathrm{HCO}_{3}$,

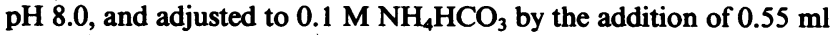
$2 \mathrm{M} \mathrm{NH}_{4} \mathrm{HCO}_{3}, \mathrm{pH} \mathrm{8.0}$. The solution was applied to the column at a rate of $16 \mathrm{ml} / \mathrm{h}$. The column was washed with $128 \mathrm{ml}$ of $0.1 \mathrm{M}$ $\mathrm{NH}_{4} \mathrm{HCO}_{3} \mathrm{pH} 8.0$ and collected into 8-ml fractions. After washing, a linear gradient was started $\left(0.1 \mathrm{M}\right.$ to $1 \mathrm{M} \mathrm{NH}_{4} \mathrm{HCO}_{3}, \mathrm{pH} \mathrm{8.0)}$ at a flow rate of $8 \mathrm{ml} / \mathrm{h}$ and collected in $4.0-\mathrm{ml}$ fractions. All fractions were lyophilized and resuspended in $1 / 10$ their original volume with 5 mM HAc containing $2 \mathrm{mg} / \mathrm{ml} \mathrm{BSA}$, and assayed for PDGF competitor and for total mitogenic activity. Elution profile shows total competitor and mitogen activities in nanograms PDGF equivalent/fraction.

observations together with our finding that rat $\mathrm{MC}$ produce a PDGF-like protein raises the possibility that rat MC by producing a PDGF-like protein may regulate their own growth properties. Such an autocrine mechanism by which cells synthesize a growth factor capable of promoting their own proliferation was first proposed to explain the growth properties of transformed cells $(49,50)$. More recently, other instances for autocrine regulation of growth of normal cells have been postulated for smooth muscle cells cultured from pup rats (17) and for cytotrophoblasts cultured from first trimester human placentas (51). In this context, it is noteworthy that MC proliferation may be seen in some glomerular diseases characterized by the absence of infiltrating inflammatory cells or platelets.

Growth factors may also influence the growth properties of neighboring cells, by a mechanism referred to as a paracrine effect $(39,51)$. Striker et al. (52) reported that the addition of PDGF to isolated human glomeruli results in proliferation of glomerular endothelial cells that constituted the majority of primary glomerular cell outgrowth. This observation also raises the possibility that PDGF produced by MC may function in a short range paracrine manner to regulate the proliferation of neighboring glomerular endothelial cells. Endothelial cell proliferation is also seen in a variety of glomerular diseases (53). Moreover, PDGF released by MC may be responsible for the regeneration of denuded glomerular endothelial cells, also seen in certain forms of glomerular injury. Determining the signals and mechanisms that operate to regulate PDGF production by $\mathrm{MC}$ and localizing the glomerular cell type that may serve as a target for PDGF may provide further insight for understanding the pathogenesis of glomerular diseases.

\section{Acknowledgments}

The authors thank Dr. M. Hassan and the electron microscopy unit at the Veterans Administration Medical Center for doing the electron microscopy studies, Ruby Turner for technical assistance, and Sandy Evans for typing the manuscript.

This work was supported through the Veterans Administration research funds, and the National Institutes of Health grants AM-33665 and HL-29582. Dr. Abboud is an Established Investigator of the American Heart Association and Dr. DiCorleto is a recipient of Research Career Development Award (HL-10561) from National Institutes of Health.

\section{References}

1. Kriesberg, J. I., and M. J. Karnovsky. 1983. Glomerular cells in culture. Kidney Int. 24:439-447.

2. Foidart, J. B., C. A. Dechene, P. Mahieu, C. A. Creutz, and J. DeMey. 1979. Tissue culture of normal rat glomeruli. Isolation and characterization of two homogenous cell lines. Invest. Cell Pathol. 2:5-26.

3. Schor, N., I. Ichikawa, and B. M. Brenner. 1981. Mechanisms of action of various hormones and vasoactive substances on glomerular ultrafiltration in the rat. Kidney Int. 20:442-451.

4. Ausiello, D. A., J. I. Kreisberg, C. Roy, and M. J. Karnovsky. 1980. Contraction of cultured rat glomerular mesangial cells after stimulation with angiotensin II and arginine vasopressin. J. Clin. Invest. 65:754-760.

5. Scharschmidt, L. A., and M. J. Dunn. 1983. Prostaglandin synthesis by rat glomerular mesangial cells in culture: the effects of angiotensin II and arginine vasopressin. J. Clin. Invest. 71:1756-1764.

6. Sedor, J., and H. E. Abboud. 1985. Histamine modulates contraction and cyclic nucleotides in cultured rat mesangial cells. Differential effects mediated by $\mathrm{H}_{1}$ and $\mathrm{H}_{2}$ receptors. J. Clin. Invest. 75:1679-1689.

7. Kreisberg, J. I. 1982. Insulin requirement for contraction of cultured rat glomerular mesangial cells in response to angiotensin II: Possible role for insulin in modulating glomerular hemodynamics. Proc. Natl. Acad. Sci. USA. 79:4190-4192.

8. Baud, L., J. Hagege, J. Sraer, E. Rondeau, J. Perez, and R. Ardaillou. 1983. Reactive oxygen production by rat glomerular mesangial cells during phagocytosis is associated with stimulation of 12 lipoxygenase activity. J. Exp. Med. 158:1832-1856.

9. Lovett, D. H., R. B. Sterzel, M. Kashgarian, and J. L. Ryan. 1983. Neutral proteinase activity produced in vitro by cells of the glomerular mesangium. Kidney Int. 23:342-349.

10. Kurtz, A., W. Jelkmann, F. Sinowatz, and C. Bauer. 1983. Renal mesangial cell cultures as a model for study of erythropoietin production. Proc. Natl. Acad. Sci. USA. 80:4008-4011.

11. Lovett, D. H., J. L. Ryan, and R. B. Sterzel. 1983. A thymocyte-activating factor derived from glomerular mesangial cells. J. Immunol. 130:1796-1801.

12. Ross, R., J. Glomset, B. Kariya, and L. Harker. 1974. A platelet-dependent serum factor that stimulates the proliferation of arterial smooth muscle cells. Proc. Natl. Acad. Sci. USA. 71:1207-1210.

13. Westermark, B., C. H. Heldin, B. Ek, A. Johnson, K. Mellstrom, M. Nister, and A. Wasteson. 1983. Biochemistry and biology of platelet-derived growth factor. In Growth and Maturation Factors. G. Guroff, editor. John Wiley and Sons, New York. pp. 73-115.

14. Stiles, C. D. 1983. The molecular biology of platelet-derived growth factors. Cell. 33:653-655. 
15. Deuel, T. F., and J. S. Huang. 1984. Platelet-derived growth factor: structure, function and roles in normal and transformed cells. $J$. Clin. Invest. 74:669-676.

16. Scher, C. D., R. C. Shepard, N. H. Antoniades, and C. D. Stiles. 1979. Platelet-derived growth factor and the regulation of the mammalian cell cycle. Biochim. Biophys. Acta. 560:217-241.

17. Heldin, C. H., B. Westermark, and A. Wasteson. 1980. Chemical and biological properties of a growth factor from human cultured osteosarcoma cells: resemblance with platelet-derived growth factor. $J$. Cell. Physiol. 105:235-246.

18. Nister, M., C. H. Heldin, A. Wasteson, and B. Westermark. 1984. A glioma-derived analog to platelet-derived growth factor: Demonstration of receptor competing activity and immunological crossreactivity. Proc. Natl. Acad. Sci. USA. 81:926-930.

19. Bowen-Pope, D. F., A. Vogel, and R. Ross. 1984. Production of platelet-derived growth factor-like molecules and reduced expression of platelet-derived growth factor receptors accompany transformation by a wide spectrum of agents. Proc. Natl. Acad. Sci. USA. 81:23962400.

20. Pantazis, P., P. G. Pelicci, R. Dalla-Favera, and H. N. Antoniades. 1985. Synthesis and secretion of proteins resembling plateletderived growth factor by human glioblastoma and fibrosarcoma cells in culture. Proc. Natl. Acad. Sci. USA. 82:2404-2408.

21. DiCorleto, P. E., and D. F. Bowen-Pope. 1983. Cultured endothelial cells produce a platelet-derived growth factor-like protein. Proc. Natl. Acad. Sci. USA. 80:1919-1923.

22. Seifert, R. A., S. M. Schwartz, and D. F. Bowen-Pope. 1984. Developmentally regulated production of platelet-derived growth factor-like molecules. Nature (Lond.). 311:669-671.

23. Fox, P. L., and P. E. DiCorleto. 1984. Regulation of production of a platelet-derived growth factor-like protein by cultured bovine aortic endothelial cells. J. Cell. Physiol. 121:298-308.

24. DiCorleto, P. E., C. M. Gajdusek, S. M. Schwartz, and R. Ross. 1983. Biochemical properties of the endothelium-derived growth factor: Comparison to other factors. J. Cell. Physiol. 114:339-345.

25. DiCorleto, P. E. 1984. Cultured endothelial cells produce multiple growth factors for connective tissue cells. Exp. Cell Res. 153:167-172.

26. Raines, E. W., and R. Ross. 1982. Platelet-derived growth factor. I. High yield purification evidence for multiple forms. J. Biol. Chem. 257:5154-5160.

27. Bowen-Pope, D. F., and R. Ross. 1982. Platelet-derived growth factor. II. Specific binding to cultured cells. J. Biol. Chem. 257:51615171 .

28. Bowen-Pope, D. F., and R. Ross. 1984. Methods for studying the platelet-derived growth factor receptor. Methods Enzymol. 109:69-100.

29. Madri, J. A., F. J. Roll, H. Furthmayr, and J. M. Foidart. 1980 The ultrastructural localization of fibronectin and laminin in the basement membrane of the murine kidney. J. Cell Biol. 86:682-687.

30. Neels, H. M., M. E. van Sande, and S. L. Scharpe. 1983. Sensitive colorimetric assay for angiotensin converting enzyme in serum. Clin. Chem. 29:1399-1403.

31. Bowen-Pope, D. F., P. E. DiCorleto, and R. Ross. 1983. Interactions between the receptors for platelet-derived growth factor and epidermal growth factor. J. Cell Biol. 96:679-683.

32. Haigler, H. T., F. R. Maxfield, M. C. Willingham, and I. Pastan. 1980. Dansylcadaverine inhibits internalization of ${ }^{125} \mathrm{I}$-epidermal growth factor in BALB 3T3 cells. J. Biol. Chem. 255:1239-1241.

33. Senior, R. M., G. L. Griffin, J. S. Huang, D. A. Walz, and T. F. Deuel. 1983. Chemotactic activity of platelet alpha granule proteins for fibroblasts. J. Cell Biol. 96:382-385.

34. Deuel, T. F., R. M. Senior, J. S. Huang, and G. L. Griffin. 1982. Chemotaxis of monocytes and neutrophils to platelet-derived growth factor. J. Clin. Invest. 69:1046-1049.
35. Williams, L. T., H. N. Antoniades, and E. J. Goetzl. 1983. Platelet-derived growth factor stimulates mouse 3T3 cell mitogenesis and leukocyte chemotaxis through different structural determinants. $J$. Clin. Invest. 72:1759-1763.

36. Seppar, H., G. R. Grotendorst, S. Seppa, E. Schiffmann, and G. R. Martin. 1982. Platelet-derived growth factor is chemotactic for fibroblasts. J. Cell Biol. 92:584-588.

37. Grotendorst, G. R., H. E. J. Seppa, H. K. Kleinman, and G. R. Martin. 1981. Attachment of smooth muscle cells to collagen and their migration toward platelet-derived growth factor. Proc. Natl. Acad. Sci. USA. 78:3669-3672.

38. Grotendorst, G. R., T. Chang, H. E. J. Seppa, H. K. Kleinman, and G. R. Martin. 1982. Platelet-derived growth factor is a chemoattractant for vascular smooth muscle cells. J. Cell. Physiol. 113:261266.

39. Tzeng, D. Y., T. F. Deuel, J. S. Huang, R. M. Senior, L. A. Boxer, and R. L. Baehner. 1984. Platelet-derived growth factor promotes polymorphonuclear leucocyte activation. Blood. 64:1123-1128.

40. Tzeng, D. Y., T. F. Deuel, J. S. Huang, and R. L. Baehner. 1985. Platelet-derived growth factor promotes human peripheral monocyte activation. Blood. 66:178-183.

41. Cochrane, C. G., E. R. Unanue, and F. J. Dixon. 1965. A role of polymorphonuclear leukocytes and complement in nephrotoxic nephritis. J. Exp. Med. 122:99-119.

42. Unanue, E. R., G. F. Schreiner, and R. S. Cotran. 1982. A role of mononuclear phagocytes in immunologically induced glomerulonephritis. In Immune Mechanism in Renal Disease. N. B. Commings, A. F. Michael, and C. B. Wilson, editors. New York, Plenum Publishing Corp. pp. 443-451.

43. Holdsworth, S. R., T. J. Neale, and C. B. Wilson. 1981. Abrogation of macrophage-dependent injury in experimental glomerulonephritis in the rabbit. Use of an anti-macrophage serum. J. Clin. Invest. 68:686-698.

44. Magil, A. B., L. O. Wadsworth, and M. Loewen. 1981. Monocytes and human renal glomerular disease. A quantitative evaluation. Lab. Invest. 45:27-33.

45. Bachmann, S., W. Kriz, C. Kuhn, and W. W. Franke. 1983. Differentiation of cell types in the mammalian kidney by immunofluorescence microscopy using antibodies to intermediate filament proteins and desmoplakins. Histochemistry. 77:365-394.

46. Lovett, D. H., J. L. Ryan, and R. B. Sterzel. 1983. Stimulation of rat mesangial cell proliferation by macrophage interleukin $1 . J$. Immunol. 131:2830-2836.

47. Striker, G. E., P. D. Killen, and F. M. Farin. 1980. Human glomerular cells in vitro: isolation and characterization. Transplant. Proc. 12(Suppl. 1):88-99.

48. Nakashima, Y., S. Hirose, and Y. Hamashima. 1980. Proliferation of cultured rabbit renal glomerular cells stimulated by platelet factor. Acta Pathol. Jpn. 30:1.

49. Sporn, M. B., and G. J. Todaro. 1980. Autocrine secretion and malignant transformation of cells. N. Engl. J. Med. 15:878-880.

50. Kaplan, P. L., M. Anderson, and B. Ozanne. 1981. Transforming growth factors production enables cells to grow in the absence of serum: An autocrine system. Proc. Natl. Acad. Sci. USA. 79:485-489.

51. Goustin, A. S., C. Bethsholtz, S. Pfeifer-Ohlsson, H. Persson, J. Rydnert, M. Bywater, G. Holmgren, C.-H. Heldin, B. Westermark, and R. Ohlsson. 1985. Coexpression of the sis and myc proto-oncogenes in developing human placenta suggest autocrine control of trophoblast growth. Cell. 41:301-312.

52. Striker, G. E., C. Sodeland, D. F. Bowen-Pope, A. M. Gown, G. Schmer, A. Johnson, D. Luchtel, R. Ross, and L. J. Striker. 1984. Isolation, characterization and propagation in vitro of human glomerular endothelial cells. J. Exp. Med. 160:322-328.

53. Heptinstall, R. H. 1974. Pathology of the Kidney. 2nd edition. Little, Brown \& Co., Boston. pp. 331-369. 